\title{
Lean supply chain planning
}

\author{
Rob Kwikkers \\ IPL Consultants BV, Veldhoven, the Netherlands. \\ Email: kwikkers@ipl.nl
}

\begin{abstract}
This paper reviews some problems and solution strategies to overcome the problems of short forecast horizons, changing forecasts and short term demand variations in a long supply chain. The purpose is to identify the potential for and limits to the use of integral information for optimizing the performance of the chain as a whole.

The points highlighted in this paper are not new, but well described in literature and even older study books. In practice, however, these lessons seem to have been forgotten, and expectations of collaborative systems are based on false assumptions. One of the main false expectations is that the "bullwhip effect" (of amplification of demand variations to the upstream processes) can be avoided with integral information communication in the supply chain. Rather, the bullwhip effect is inherent in a long supply chain, and planners can only employ strategies to ward off the adverse effects.

Another false expectation is that integral availability of information throughout the chain will automatically lead to better performance. On the contrary, indiscriminate use of all new information will only cause a very nervous system. Integral information is only the beginning of improvement, it merely provides a sound basis for trade-offs that need to be made throughout the chain. The main trade-offs that supply chain planners must make are between forecasting effort, capacity change costs (order nervousness), and investment in buffer inventories. Existing work on these trade-offs should be taken into account when designing new supply chain management solutions. This paper tries to bring these trade-offs and the theory that drives them back into the focus of developers of modern systems.

In the internal supply chain of a large company the trade-offs can be made to optimize the whole. Useful future work can be done on supporting these trade-offs in networks of independent parties: often one party must make efforts to improve the performance and bring benefits for another participant. Management reporting must be carefully designed to support inter-company trade-offs, choices, highlight causes and effects.
\end{abstract}

\section{Keywords}

Supply chain planning strategies, integral production and inventory management, bullwhip effect, supply chain modelling.

\section{INTRODUCTION: AVAILABILITY AND USE OF INTEGRAL INFORMATION}

The goal of organizations that collaborate in a supply chain is to run the business lean but reliable. They strive towards the lowest possible inventory 
investment and risk while maintaining a high service level and stable flows throughout the chain. Many believe that information sharing between the partners in the chain is a main step towards achieving these goals. In recent years, information systems have developed to such a level that some organizations have reached this information sharing practice.

Now the challenge lies with supply chain planners to use this shared information wisely and achieve a supply chain with lean characteristics. In their daily practice, supply chain planners must decide on varying the ordering levels and chain inventory positions. For consistent behaviour, they need to guide their decisions with clear strategies.

This paper first explains the well known problem of the "bullwhip effect" of amplifying small changes while adjusting the flow content of a long pipeline to demand variations. The paper then explores various strategies to avoid adverse effects of this bullwhip effect. It explores the optimal use of integral information, the pro's and con's of coordinated ordering in the pipeline, and inventory strategies to overcome lead-time and capacity limitations.

\section{MANAGING THE PIPELINE FLOW CONTENT}

To the disappointment of integral supply chain planners, it turns out that even with full collaboration and information sharing, it is difficult to practice lean planning in a long supply chain which is plagued by rises and falls demand. If reaction times in the chain are long, the pipeline content is considerable. This creates a sizeable "bullwhip effect" [Forrester 1961] while anticipating and following the demand. By this effect, the rational planning aim to keep the supply pipeline as lean as possible results in enormous requirement waves in the upstream part of the chain.

Figure 1 depicts a simple supply chain with a length of 12 weeks. A component factory takes 3 weeks to produce into a component stock point, that contains 1 week demand as buffer (for example to smooth cyclic production and optimize transport). From this stock point, a product factory takes 4 weeks to make finished products, which it delivers to a products stock that contains 1-week demand. Distribution to various warehouses takes 1 week, and the warehouses contain 2 weeks demand in buffer stock (for example to overcome short term demand variations).

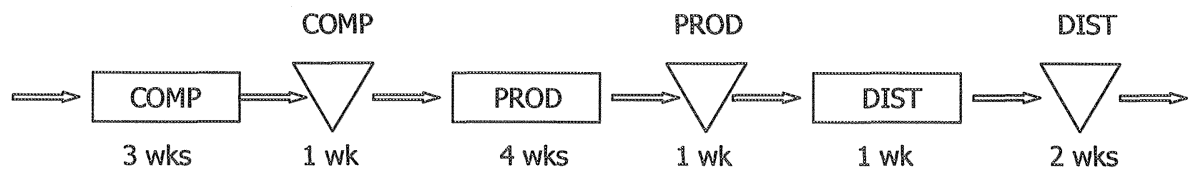

Figure 1 - example supply chain

\section{The necessary size of the pipeline flow content}

To sustain a flow, a pipeline has to be filled with an amount of materials that is equal to the flow in the pipeline times the length of the pipeline. As illustrated in the examples in Figure 2 below, if a pipeline has to maintain a continuous flow of 10 pieces per week and the length of the pipeline is 12 weeks, the flow content of the 
pipeline necessarily is 120 pieces. If (in high season) this pipeline has to sustain a flow of 20 pieces per week, the necessary flow content is 240 pieces. A shorter pipeline of 8 weeks length would sustain a flow of 20 pieces per week with a content of only 160 pieces.

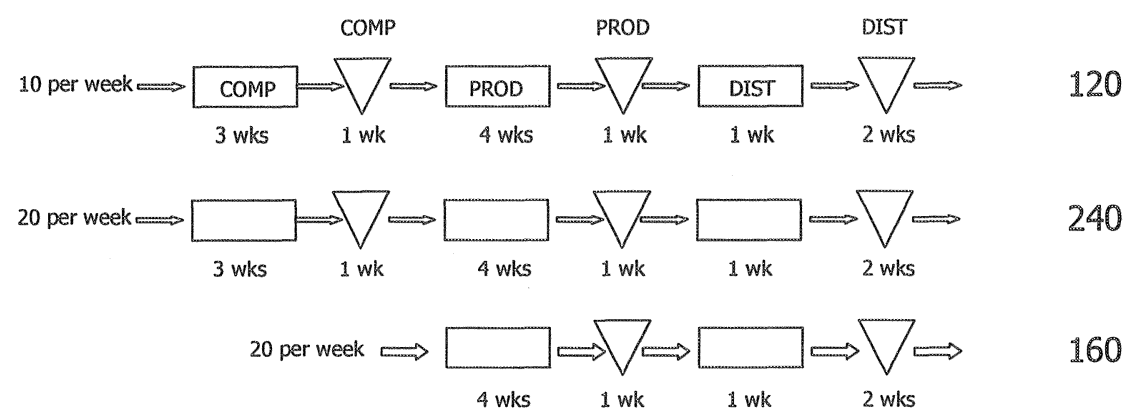

Figure 2 - pipeline flow content

\section{Adjusting the pipeline content to fit the demand flow}

In the above we have seen, different pipeline flow rates require different pipeline flow content. As a consequence, when a pipeline is subject to varying demand (projections), the pipeline content needs to be brought up and down continuously.

The problem is that the amount of materials to be added to and drained from the pipeline may easily be a multitude of the demand flow rate. Figure 3 shows in its first line that to sustain a flow of 4 pieces per week; the pipeline content is 48 pieces in stock or work-in-process. An "upstream" order of 4 pieces on the component factory is sufficient to keep this pipeline going.

\begin{tabular}{|c|c|c|c|c|c|c|c|c|}
\hline & \multicolumn{6}{|c|}{ PIPEUNE (weeks) } & \multirow[b]{3}{*}{$\begin{array}{c}\text { DEMAND } \\
\text { FCST }\end{array}$} \\
\hline & & 3 & 1 & 4 & 1 & 1 & 2 & \\
\hline $\begin{array}{l}\text { UPSTREAM } \\
\text { ORDER }\end{array}$ & $\begin{array}{l}\text { PIPELINE } \\
\text { CONTENT }\end{array}$ & COMP & $\begin{array}{c}\text { COMP } \\
\text { BUFFER }\end{array}$ & PROD & $\begin{array}{c}\text { PROD } \\
\text { BUFFER }\end{array}$ & DIST & $\begin{array}{c}\text { DIST } \\
\text { BUFFER }\end{array}$ & \\
\hline & & & & & & & & \\
\hline 4 & 48 & 12 & 4 & 16 & 4 & 4 & 8 & 4 \\
\hline 17 & 60 & 15 & 5 & 20 & 5 & 5 & 10 & 5 \\
\hline 5 & 60 & 15 & 5 & 20 & 5 & 5 & 10 & 5 \\
\hline-8 & 48 & 12 & 4 & 16 & 4 & 4 & 8 & 4 \\
\hline 4 & 48 & 12 & 4 & 16 & 4 & 4 & 8 & 4 \\
\hline 30 & 72 & 18 & 6 & 24 & 6 & 6 & 12 & 6 \\
\hline 19 & 84 & 21 & 7 & 28 & 7 & 7 & 14 & 7 \\
\hline
\end{tabular}

Figure 3 - adjusting the pipeline flow content to the customer demand forecast

The second line of the table shows that to sustain a flow of 5 pieces per week, the pipeline content must be at 60 pieces. To adjust the pipeline content and cover the increased demand rate, an upstream need of 17 pieces on the component factory is generated. This extra need for 12 pieces represents 3 weeks of normal demand! The third line in the table shows the stable situation with a demand flow of 5 pieces per week. An upstream order of 5 is sufficient. If the demand drops back, the situation reverses, and the pipeline needs to be drained from 12 pieces. Since the 
demand is now stable at 4 pieces per week, the component factory should fully stop production for 3 weeks! The remainder of the table illustrates two steps of upstream order behaviour when the demand increases in season.

The simple example above illustrates that even small variations in customer demand cause sizeable variation in the upstream orders. This effect is known as the "bullwhip" effect [Lee, 1997], reminiscing that the end of the whip moves much more violent than the handle.

\section{The "bullwhip" effect}

In the previous section, the bullwhip effect is shown for the upstream orders only, but of course it also affects the intermediate parts of the chain, though less severely. In Figure 4 , the reaction ${ }^{1}$ of a four-stage supply chain to variations in customer demand is shown.

The demand pattern is seasonal, with a dip in the middle of "summer". The distribution centre orders swing stronger than the demand, because it has to account not only for the increased demand, but also to increase the flow content under its responsibility. The products factory has to react even stronger, because in addition to the increased demand and the corrections the distribution centre made, it needs to adjust the flow content under its own responsibility. In the same manner, the components and materials factories get to cope with even larger upswings and downswings

Orders

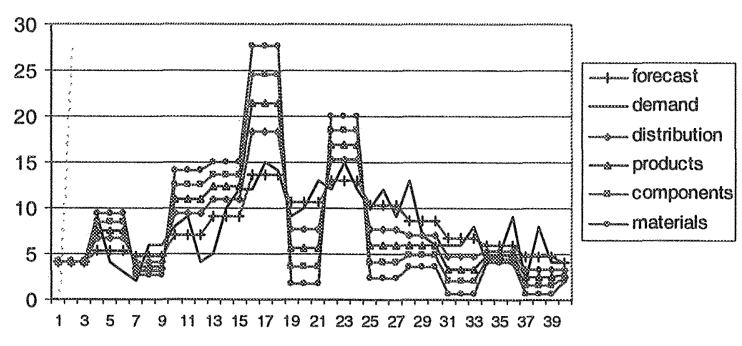

Figure 4 - the "bull-whip" effect of orders adjusting the pipeline content

The seemingly erratic ordering behaviour upstream in the supply chain is a major complaint in many supply chains, where the large swings usually cannot be followed by capacity adjustments. The above shows, however, that the bullwhip effect that causes these ordering swings is simply a part of life, and not bad management.

${ }^{1}$ For stability of the production system the forecast average demand over three periods is taken as a basis for reaction, and the build-up and draining is planned in these three periods. 


\section{USING FORECAST INFORMATION}

The best way of fulfilling the high build-up and build-down of upstream pipeline content is starting early, and pushing the needed materials into the chain according to the future needs. Instead of fulfilling the bullwhipped needs with high orders and high capacity needs, an early start allows the production system to fulfil the demand by anticipation and with lower capacity.

Figure 5 below depicts the order behaviour to a sudden (and lasting) rise in demand. In the leftmost graph the event not expected, and the whole supply chain must react immediately. The bullwhip effect causes high upstream orders. In the rightmost graph, the rise in demand was foreseen. The upstream parts of the supply chain can now anticipate the increased needs by starting their production early and "flowing" the materials through the chain. As a result, the capacity needs everywhere remain very stable.

In today's world with rapid product changes and stiff competition it is difficult to forecast. New products may "ramp-up" and old ones "phase-out" at a different rate than expected, short-term economic events may change the demand flow of even mature products. Supply chain planners are often confronted with the task of implementing significant changes to the forecast on short notice: creating bullwhipped orders.
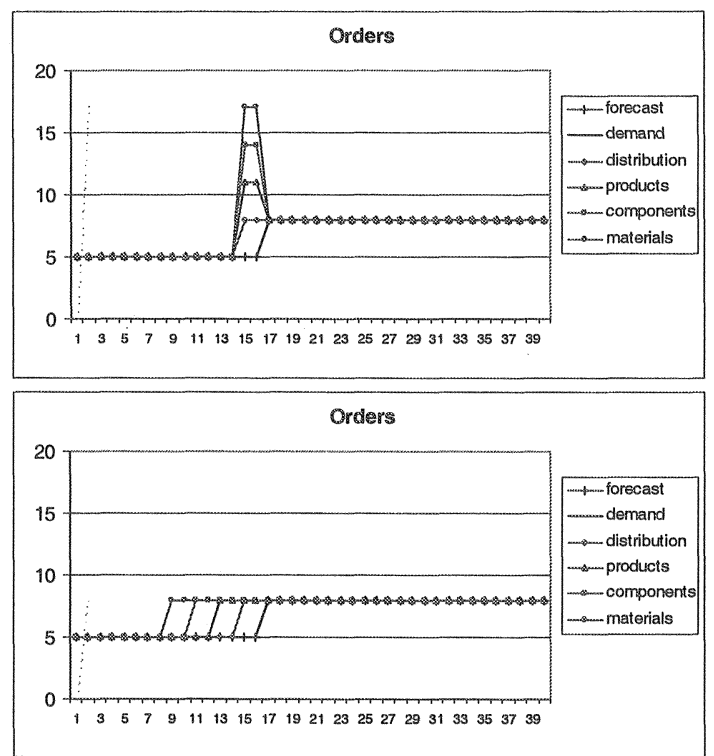

Figure 5 - Reacting to an unexpected event vs. anticipating by forecast 


\section{AVOIDING PIPELINE NERVOUSNESS}

With modern systems, information can be easily made available throughout the supply chain. Point of sale terminals provide current demand information, warehouse systems or vendor managed inventory make actual inventory levels and pending replenishment orders visible. With this information, estimations of future demand flows can be reviewed frequently and with ease. Considering, however, that small changes in demand or short term forecast create high fluctuations in the upstream part of the supply chain, it is important to show restraint in communicating changes up the chain. This feels awkward in light of the abundance of available information and the ability for fast communication, but too many changes only create nervousness in the chain. Two questions arise:

1. How should the upstream parts of the chain react to an updated short term forecast, and

2. What should be done with information about the real customer demand?

\section{Reacting on short term forecast updates}

While time progresses, new information on expected customer demand becomes available and the forecast can be updated. Especially when demand has a high variation an no reliable longer term information is available, the new information tends to impact the forecast significantly. Recent events may alternatively suggest a change in trend, and swift reaction on this generates nervousness in the chain. If a forecast is re-evaluated over a longer period, the significance of short term events may be better placed in proportion.

In Figure 6, the ordering and inventory consequences of two forecast updating strategies are presented: an immediate update and a five-weekly update. Both strategies use a five week moving average of the same demand data. In the depicted strategies, the forecasted five period moving average is communicated up the chain after each period, or once every five periods. In this example, the upstream players in the supply chain adjust their pipeline content to fit the expected flow. They bring about the necessary adjustments in the periods that available before the next forecast update.

From the graphs it can be seen that immediate reaction to forecast updates creates more nervousness in the supply chain. The order quantities differ significantly from period to period. The bullwhip effect amplifies moderate demand forecast fluctuations into major upstream order nervousness. The 5 period forecast update, as seen in the right side of the Figure, gives a more consistent ordering behaviour.

The consistent ordering behaviour comes at a cost, however. The fact that available information (on the moving average) is not used immediately, makes the upper parts of the chain react slower. To overcome these slow reactions while still maintaining delivery performance, higher buffer inventories are needed throughout the chain.

There clearly is a trade-off to be made between nervousness and inventory position. In many chains, capacity changes (adding people, adding shifts, subcontracting) are costly and need to be prepared well in advance. Periodic reaction 
to updated forecast provides this preparation time. Being aware of the bullwhip effect, demand forecasters should be very cautious with making changes to the forecast. They must make very sure that a perceived increase or decrease in demand is indeed a significant change that justifies upsetting the upstream partners in the supply chain.

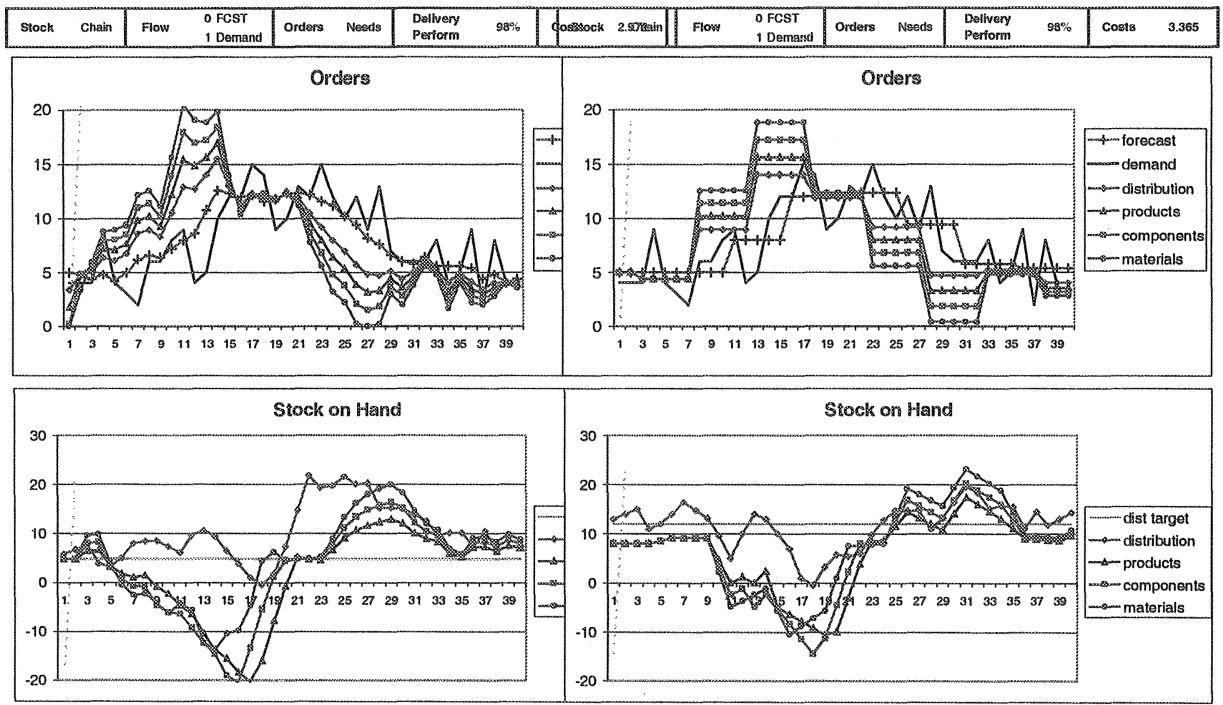

Figure 6 -Immediate vs. periodic forecast updating on 5 period moving average

\section{Ordlering forecast or real demand}

In the previous section we saw that rapid reaction to news up the supply chain may not be the preferred strategy. This is also true for communicating real demand information. The question now arises if the planner should place orders according to the near part of the forecast (which accurately estimates the average demand), or if he should base his orders on the real customer orders as they become known.

In Figure 7, the leftmost graphs show the effect of ordering according to the forecast. Orders remain constant during five periods, at the sum of the requirements to adjust the pipeline content in five equal periods (based on the long-term forecast) plus the short term forecast over the next five periods.

The rightmost graphs show the effect of ordering according to the real demand throughout the chain. The real demand is now added to the orders to adjust the pipeline flow content. This makes the ordering and production in the chain much more nervous.

On the inventory graphs we can see that using the most current information does not improve the internal delivery reliability, since reaction lag time of the system prevents a swift reaction on the short-term needs anyway. Communicating real demand only creates a lot of the nervousness that supply chain planners complain about. 


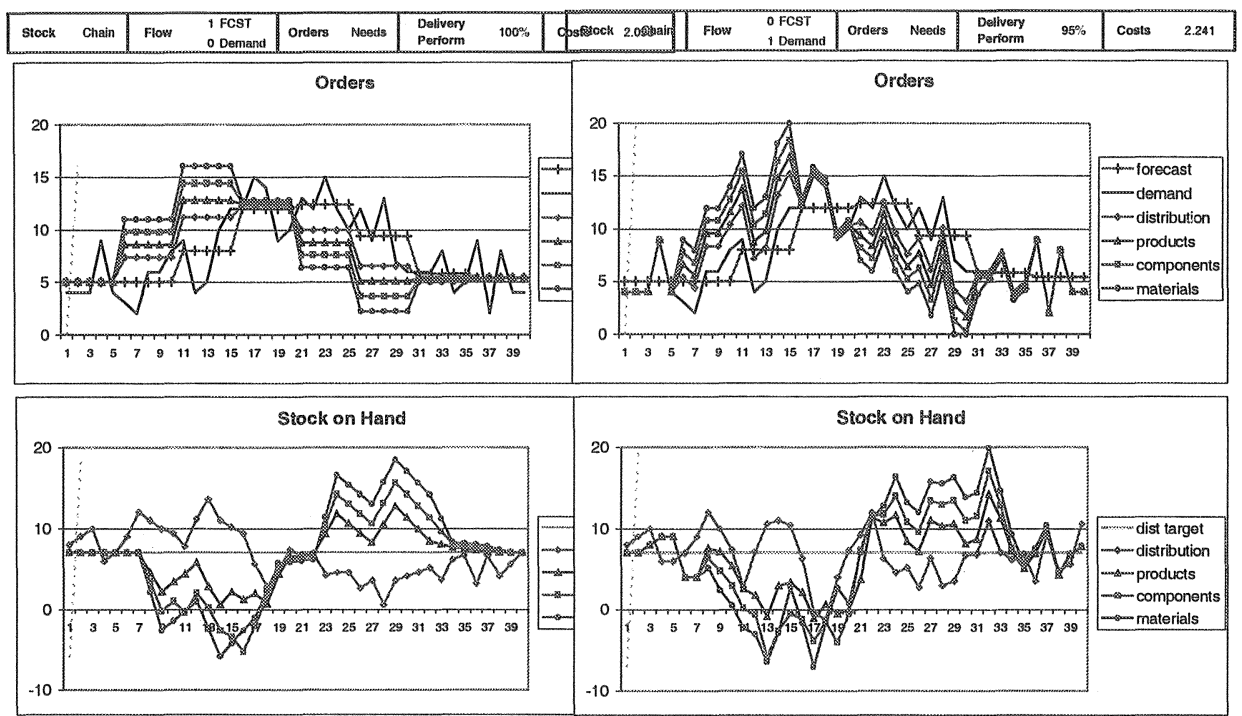

Figure 7 - Communicating forecast vs. customer demand

\section{PIPELINE ORDER COORDINATION}

On some occasions, when demand and forecast really stress the system, stock outs occur at upstream positions in the supply chain. Though these backorders are delivered as soon as possible, their effect is that the downstream processes cannot execute their production plans because of lack of components. These disruptions ruin the efficient performance and hurt the credibility of all participants in the supply chain.

The question now arises, if the planner should base his orders on the real needs he has, regardless of the supply capabilities, or if he should order the amounts that he can realistically expect to be supplied. Of course, in either case, he will receive the same amounts of goods at the same times! If the planner orders his needs, he causes backorders in the chain, and more or less fools himself in thinking that his intended production schedule can be executed. If the planner orders realistic supply, he does not communicate his real needs, and does not signal his supplier to "go the extra mile" to fulfil them. He then also has to remember that he ordered too little, and needs to place a second order for the remainder. 


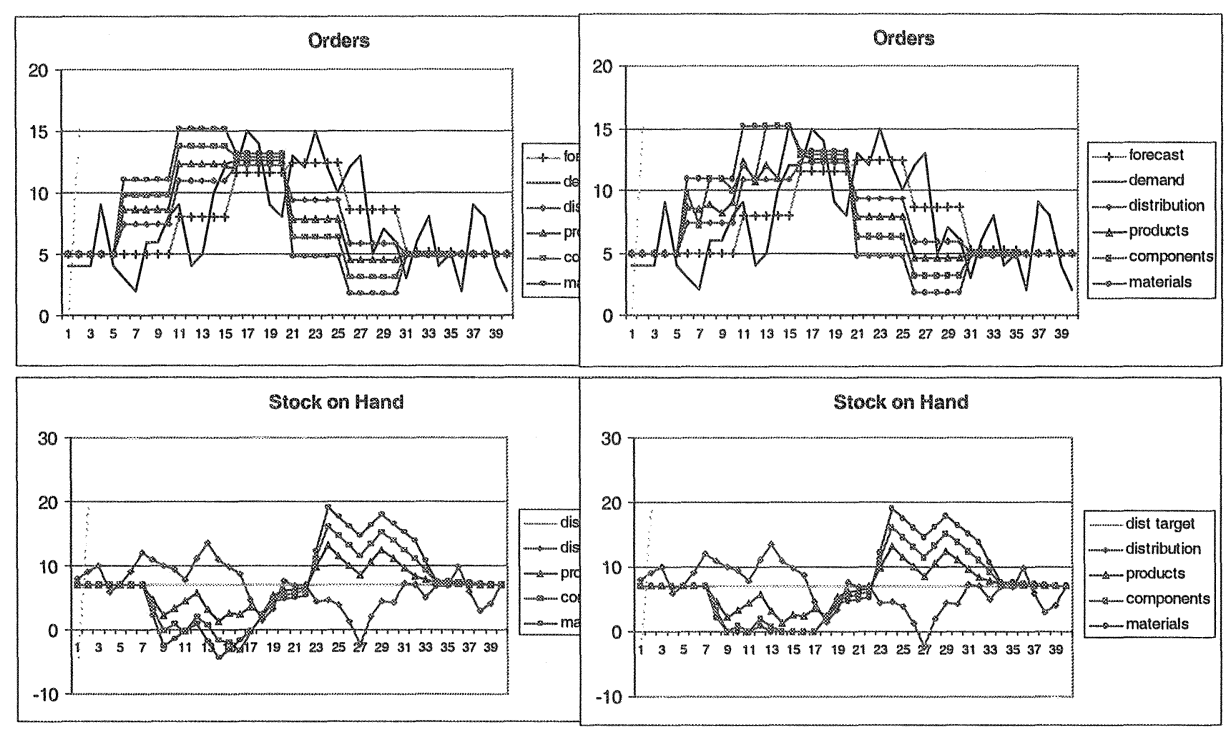

Figure 8 - ordering needs vs. ordering realistic supply

In Figure 8, the two ordering strategies are compared. In the leftmost graphs, the planners order real needs, causing stock out positions and possible confusion in the chain. In the rightmost graphs, orders are reduced or delayed to fit the realistic supply possibilities.

Comparing the leftmost and rightmost graphs, it can be seen that the delivery performance (from distribution) to the end-customer is not affected at all by the ordering behaviour in the intermediate stages. From this, it can be concluded that both informations should be communicated: real needs to trigger extra supplier effort, but realistic supply (to be fed back) to adjust downstream production plans to the likely supply situation.

\section{PIPELINE INVENTORY STRATEGY}

Lean supply chain management aims for low inventories throughout the pipeline. It is often seen as an ideal to have no inventories at all: to run the system with "Just-In-Time" (JIT) arrivals of goods. There are various reasons why JIT is impossible in chains with random varying or even seasonal demand: there must be buffer inventories to overcome the lead-times of the information flow and physical supply, and there must be inventories to compensate for the limited supply capacity of upstream production units. 


\section{Overcoming supply lead time}

In any supply chain, it takes some time to become aware of and physically react to an increase in demand. Even if information is immediately passed up the chain and upstream production is increased, it takes some time for the results to get downstream. Inventory is unavoidable for being able to fulfil the demand in the meantime.

Two strategies for placement of these inventories are depicted in Figure 9. The "downstream" strategy in the leftmost graphs relies on distribution inventory only, and runs the upstream part of the chain on a just-in-time basis. The "upstream" strategy in the rightmost graphs uses inventories that are placed at various points in the chain.

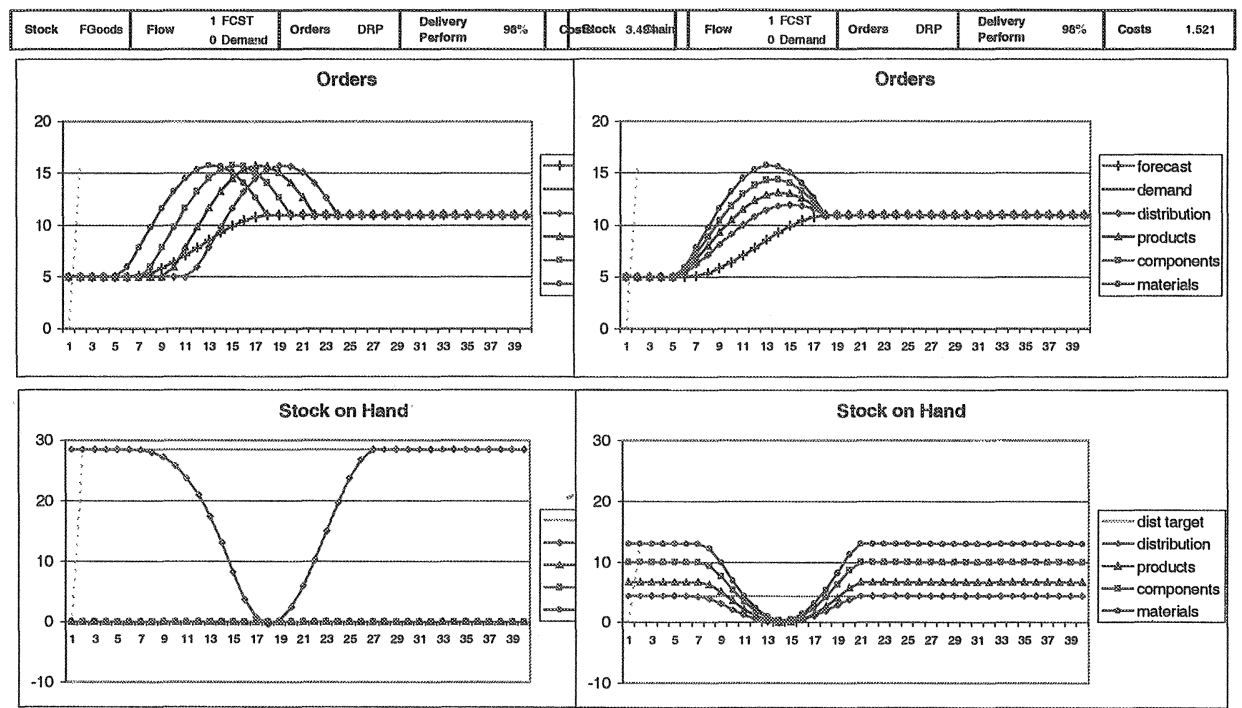

Figure 9 - inventory moved downstream or kept upstream

In the downstream inventory strategy, each of the supply chain links must wait with increases in production until additional materials have arrived from upstream. In the upstream inventory strategy, each of the supply chain links increases its production as soon as the demand increase becomes apparent.

Thus, as we can see, the upstream inventory strategy allows for a swifter reaction. It restores the condition of the downstream parts of the chain more quickly by using and depleting upstream inventories. Especially between the periods 14 and 18 , the already replenished distribution stock provides a new buffer against further demand increases. In addition, the order profile at the downstream stages of the chain is less violent. 


\section{Overcoming Capacity Limitations}

Up to now, production capacity at all stages in the pipeline has been considered extremely flexible, providing the demanded quantities as long as the upstream materials supply was sufficient. In reality, however, the ability to increase production capacity is limited, and usually even more so at the upstream processes in the supply chain. Unfortunately, the bullwhip effect requires great flexibility of these upstream processes. Assuming real capacity limitations in the upstream processes, the only remaining way to insure supply reliability is maintaining additional buffer inventories, growing more sizeable as we go upstream. These buffer inventories can be used to temporarily deliver more materials, parts and products than the upstream processes can supply.

In Figure 10, demand increases from 5 to 11 pieces in a time span of 13 periods. The capacity of processes is limited, and the limits are lower for more upstream processes.
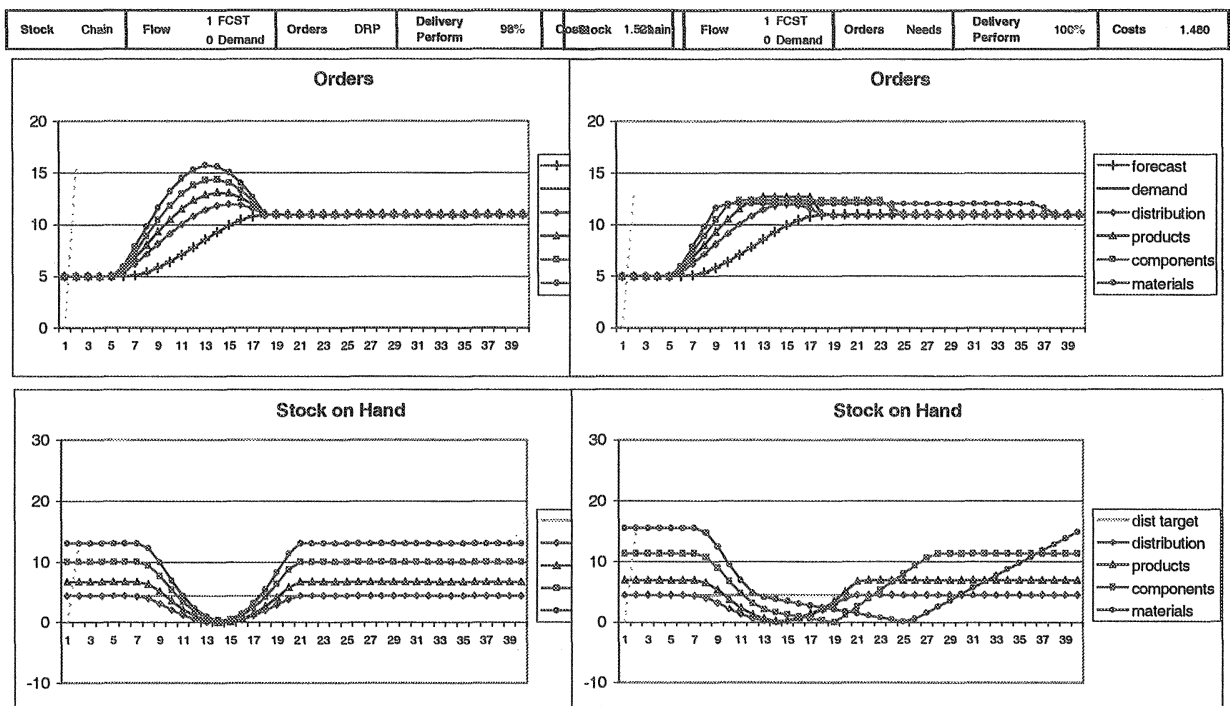

Figure 10 - unlimited vs. limited capacity

In the rightmost graphs of Figure 10, we see that it takes significantly longer to restore the upstream buffer inventory to the desired levels, and the total chain has a lower ability to cope with further rises in demand.

If this is risk unacceptable and a further rise is likely, higher inventory levels in the downstream part of the chain are needed, of course causing significantly higher costs. 


\section{LEAN SUPPLY CHAIN PLANNING}

The shown effects of the various strategies to overcome the bull-whip effect lead to the conclusion that "lean supply chain planning" is a relative idea in a world with long supply chains, varying or even seasonal demand, inadequate forecasts and limited upstream capacity flexibility. The bullwhip order effect for adjusting the pipeline content when demand is rising and falling is a part of life and cannot be avoided, so upper parts of the chain usually need more capacity flexibility than they can provide. Though forecasting helps to anticipate demand swings, it cannot solve the bullwhip and flexibility problems of demand changes within the supply leadtime. Inventories remain needed to solve short-term problems.

Integral communication of information throughout the chain helps, but reacting on every piece of new information makes the ordering behaviour very nervous and, aggravated by the bullwhip effect, suggests incompetence of supply chain planners. Realizing that inventory is an unavoidable part of life, the challenge of Lean Supply Chain Planning is not to rid the chain of all inventories, but placing them at strategic locations. All of this leads to the conclusion that integral availability of information on real demand, forecasts and inventory positions does not by itself bring about Lean Supply Chain Planning, but merely provides a good basis to search for optimal solutions.

Understanding the dynamics of the supply chain may help managers to use the abundance of information for wise decisions towards planning a lean supply chain. The "MIT Beer Distribution Game", a model of which all the graphs in this paper were taken, can be used fruitfully to make managers understand the dynamic behaviour of a supply chain. Experiments with this game [Sterman 1989] have shown that many supply chain managers underestimate the effects of the bullwhip and the information and transport time lags.

Trade-offs that these managers daily make must therefore be supported with carefully designed reports and simulations that show the effects of their decisions on the performance of various parts of the chain. These become even more interesting when optimization needs to take place in a chain or network of independent companies.

\section{REFERENCES}

[1] Burbidge, John.L. "Five Golden Rules to avoid bankruptcy" Production Engineer, 62(10), 1983.

[2] Christopher, Martin G., Logistics and Supply Chain Management. 2nd ed. Englewood Cliffs, NJ: Prentice-Hall, 1998.

[3] Clark A., and H. Scarf, "Optimal policies for a multi-echelon inventory problem", Management Science, 6(4), 1960, 465 - 490.

[4] Evans, G., M. Naim, and D. Towill, "Dynamic Supply Chain performance: assessing the impact of information systems". Logistics Information Management, 6(4) 1993, 15 - 25.

[5] Forrester, Jay W. Industrial Dynamics. Cambridge, The MIT Press, 1961.

[6] Hax, Arnoldo C., and D. Candea, Production and Inventory Management. Englewood Cliffs, NJ: Prentice-Hall, 1984. 
[7] Holweg, Matthias, "Dynamic distortions in supply chains: a cause and effect analysis", in: Taylor, David and David Brunt, (ed) Manufacturing Operations and Supply Chain Management, the Lean Approach. London: Thomson Learning, 2001.

[8] Lee, H., V. Padmanabahn, and S. Whang, "Information distortion in the supply chain: the bullwhip effect". Management Science 43(4), 1997, 546 - 558.

[9] Lee, H., V. Padmanabahn, and S. Whang, "The bullwhip effect in supply chains", Sloan Management Review, 38(3), 1997, 93 - 102.

[10] Kwikkers, Robert, Models of forecast uncertainty and flexibility inventories. Ph.D. thesis, The University of Michigan, Ann Arbor, MI: University Microfilms, 1987

[11] Silver, Edward A., and Rein Peterson, Decision sysiems for inventory management and production planning, New York, NY: John Wiley \& sons, 1985.

[12] Sterman, J.D. "Modelling managerial behaviour; misperceptions of feedback in a dynamic decision making environment". Management Science 35(3), 1989, 321 - 399.

[13] Taylor, David, "An approach to the identification and elimination of demand amplification across the supply chain", in: Taylor, David and David Brunt, (ed) Manufacturing Operations and Supply Chain Management, the Lean Approach. London: Thomson Learning, 2001.

[14] Towill D., and M. Naim, "Supply chain partnership sourcing smoothes supply chain dynamics". Purchasing and Supply Management, July/August 1993, 38 - 42.

[15] Wikner, J., D. Towell and M. Naim, "Smoothing supply chain dynamics", International journal of Production Economics, 22, 1991, 231 - 248. 